\title{
Lentiviral vector mediated modification of mesenchymal stem cells \& enhanced survival in an in vitro model of ischaemia
}

\author{
Lisa McGinley ${ }^{1}$, Jill McMahon ${ }^{2}$, Padraig Strappe ${ }^{3}$, Frank Barry ${ }^{1}$, Mary Murphy ${ }^{1}$, Daniel OToole ${ }^{4}$ and Timothy O'Brien ${ }^{1 *}$
}

\begin{abstract}
Introduction: A combination of gene and cell therapies has the potential to significantly enhance the therapeutic value of mesenchymal stem cells (MSCs). The development of efficient gene delivery methods is essential if MSCs are to be of benefit using such an approach. Achieving high levels of transgene expression for the required period of time, without adversely affecting cell viability and differentiation capacity, is crucial. In the present study, we investigate lentiviral vector-mediated genetic modification of rat bone-marrow derived MSCs and examine any functional effect of such genetic modification in an in vitro model of ischaemia.

Methods: Transduction efficiency and transgene persistence of second and third generation rHIV-1 based lentiviral vectors were tested using reporter gene constructs. Use of the rHIV-pWPT-EF1- $\alpha-G F P-W$ vector was optimised in terms of dose, toxicity, cell species, and storage. The in vivo condition of ischaemia was modelled in vitro by separation into its associated constituent parts i.e. hypoxia, serum and glucose deprivation, in which the effect of therapeutic gene over-expression on MSC survival was investigated.

Results: The second generation lentiviral vector rHIV-pWPT-EF1- $\alpha$-GFP-W, was the most efficient and provided the most durable transgene expression of the vectors tested. Transduction with this vector did not adversely affect MSC morphology, viability or differentiation potential, and transgene expression levels were unaffected by cryopreservation of transduced cells. Over-expression of HSP70 resulted in enhanced MSC survival and increased resistance to apoptosis in conditions of hypoxia and ischaemia. MSC differentiation capacity was significantly reduced after oxygen deprivation, but was preserved with HSP70 over-expression.
\end{abstract}

Conclusions: Collectively, these data validate the use of lentiviral vectors for efficient in vitro gene delivery to MSCS and suggest that lentiviral vector transduction can facilitate sustained therapeutic gene expression, providing an efficient tool for ex vivo MSC modification. Furthermore, lentiviral mediated over-expression of therapeutic genes in MSCs may provide protection in an ischaemic environment and enable MSCs to function in a regenerative manner, in part through maintaining the ability to differentiate. This finding may have considerable significance in improving the efficacy of MSC-based therapies.

\section{Introduction}

Mesenchymal stem cells (MSCs) represent a significant area of interest in the field of cell therapy. They are a multipotent, self-renewing cell population isolated from bone marrow, capable of differentiation into cells of different lineages including chondrocytes, osteoblasts and

\footnotetext{
* Correspondence: timothy.obrien@nuigalway.ie

${ }^{1}$ Regenerative Medicine Institute and Department of Medicine, National University of Ireland, Galway and Galway University Hospital, University Road, Galway. Ireland

Full list of author information is available at the end of the article
}

adipocytes [1]. The involvement of MSCs in tissue repair, their ability to home to sites of injury after systemic delivery $[2,3]$ and their evasion of normal host immune responses $[4,5]$ make them an attractive cell type for transplantation into various disease models. MSCs have also generated considerable attention in recent years in the gene therapy area, as possible vehicles for the delivery of therapeutic genes to sites of injury. Genetic modification of MSCs may allow further improvement of their therapeutic potential through promotion or suppression of gene expression. An additional

\section{Biomed Central}


benefit of MSCs as a gene delivery system is their lack of immunogenicity, which would confer significant advantage to gene therapy techniques, as the MSC itself may prevent a vector-induced host immune response [5-7].

Current cell-based therapeutic approaches for cardiovascular injury and disease are promising, although not without their shortcomings. MSC transplantation to the infarcted heart aims to promote repair and regeneration of the damaged cardiac tissue. Although several studies have proved somewhat successful [8], it may be possible to equip the MSCs for the in vivo environment into which they will be transplanted. Conditions of hypoxia, ischaemia and oxidative stress are associated with the infarct and its surrounding environment. In vitro studies have shown that, in the absence of oxygen, MSCs are capable of survival for a limited time [9]. A more prolonged lifespan may be necessary for MSCs to exert a desired therapeutic effect in vivo. In this respect, we hypothesize that increasing MSC survival capacity by genetic modification could afford the MSC a longer time in which to mediate repair and recovery both by direct and paracrine means, thereby enhancing their in vivo therapeutic value.

MSCs have been modified by various methods including lipid transfection and viral transduction. It is necessary to tailor the vector type chosen for MSC modification to the specific applications for which the cells are to be used. Lipid transfection of MSCs results in relatively low numbers of transgene expressing cells, approximately 30-40\% maximum [10]. Modification with viral vectors generally results in higher efficiency that may express transgene long or short term, depending on choice of vector. Our group has previously published a study comparing various in vitro modification methods for rat MSCs. It was reported that lentiviral vectors demonstrated excellent transduction of rat MSCs in contrast to adenovirus, AAV, lipid transfection and electroporation [11]. Accurate knowledge of gene transfer performances, in particular vector and promoter efficiency, is central to paving the way to preclinical and eventually human trials.

Lentiviral vectors have long since been established as having the ability to transduce a broad range of cell types efficiently, including non-dividing, senescent and terminally differentiated cells [12,13]. Lentiviral vectors integrate into the host cell genome resulting in stable long-term transgene expression. Elements to be considered upon choosing a vector type include vector generation, vector envelope and promoter type. An additional important consideration with regard to viral vector gene delivery is the possibility of epigenetic transgene suppression or inactivation by target host cells after transduction has occurred. This is of particular concern, as its occurrence may adversely affect the use of viral vectors for ex vivo stem cell modification.

The present study aims to assess lentivirus vectormediated genetic modification of MSCs, specifically transduction efficiency, durability of transgene expression and transgene or promoter "silencing" of three different lentiviral vector constructs. In addition, the effect of lentiviral vector transduction on MSC viability and differentiation capacity was examined. The effects of cell cryopreservation, cell passage number and species on transgene expression were also assessed. Further to establishing an optimal vector system for the modification of MSCs, a second objective of this study was to gain an understanding of how MSCs react to and influence post-ischaemic recovery, and to ascertain if this can be enhanced by induced therapeutic antioxidant or anti-apoptotic gene over-expression. This series of experiments included an evaluation of the survival and differentiation potential of MSCs in an in vitro model of ischaemia and its components, the main goal being to determine whether lentivirus vector-mediated overexpression of the pro-survival proteins catalase, SOD1, SOD3 and HSP70 can facilitate increased MSC survival.

\section{Materials and methods}

All reagents utilised were from Sigma-Aldrich (St. Louis, MO, USA) unless otherwise stated.

\section{Lentivirus production $\&$ titration}

The present study compared second and third generation self-inactivating (SIN) human immunodeficiency virus-1-based (HIV-1), VSV-G pseudotyped lentiviral vectors. Tat-dependent second generation lentiviral vectors consisted of rHIV-pWPT-EF1- $\alpha$-GFP-W and rHIVcPPT-CMV-GFP-W. The associated second generation packaging system production plasmids were provided by Didier Trono (Lausanne, Switzerland). Vectors were produced by standard transient transfection of a threeplasmid system into producer cells. Briefly, packaging plasmid ps-PAX2.2 (Addgene plasmid 12260), envelope plasmid pMD2.G (Addgene plasmid 12259) and either pWPT-GFP (Addgene plasmid 12255) or cPPT-CMVGFP expression plasmids were transfected into HEK293 cells using Jet PEI transfection reagent (Polyplus Transfection Inc, NY, USA) according to manufacturer's instructions. Culture medium was replaced $16 \mathrm{~h}$ posttransfection. Vector-containing supernatants were collected $48 \mathrm{~h}$ and $72 \mathrm{~h}$ post-transfection, filtered, pooled and concentrated by ultracentrifugation at 27,000 $\times \mathrm{g}$ for $3 \mathrm{~h}$. Lentivirus vector titre was determined by a quantitative real-time PCR based method, which detected stably integrated virus sequences in target HeLa cells and was expressed as transducing units per $\mathrm{ml}(\mathrm{TU} / \mathrm{ml})$. Tat-independent third generation lentivirus 
vector, PPT-PGK-GFP-WPRE, containing the WPRE element and polypurine tract with the GFP transgene under the control of the PGK promoter was produced by Genethon (Genethon, Évry Cédex, France, ref. pG3.22116) using four-plasmid transfection of 293T cells. Human Catalase, HSP70, SOD1 and SOD3 genes were cloned into the lentiviral expression plasmid pWPT using MluI and SalI restriction sites and lentiviral vectors expressing these transgenes were produced and vector titre calculated as described above.

\section{Human mesenchymal stem cell isolation and expansion}

Marrow was obtained from donors after informed consent and all procedures were approved by the Clinical Research Ethics Committee at University College Hospital (Galway, Ireland). Briefly, $30 \mathrm{ml}$ heparin-treated bone marrow aspirates were acquired in separate $6 \mathrm{ml}$ aliquots from the iliac crest of healthy donors. Aliquots were pooled, washed in PBS and cell pellets were resuspended in $10 \mathrm{ml}$ of complete human MSC medium, which consisted of low glucose DMEM, 10\% (v/v) FBS and $1 \%$ penicillin/streptomycin mix. Cells were seeded into $175 \mathrm{~cm}^{2}$ flasks at a density of $5.7 \times 10^{5}$ cells per $\mathrm{cm}^{2}$. After 5 days, non-adherent red blood cells were removed by a PBS wash and cells were re-fed with $30 \mathrm{ml}$ of complete medium per flask. When MSC colonies had reached $80-90 \%$ confluence, cells were detached with $0.25 \% \operatorname{trypsin}(\mathrm{w} / \mathrm{v}) / 1 \mathrm{mM}$ EDTA solution, re-plated at $5.7 \times 10^{3}$ cells per $\mathrm{cm}^{2}$ with subsequent subculture, usually at 4-6 day intervals.

\section{Rat mesenchymal stem cell isolation and expansion}

All procedures involving animals were performed in accordance with the ethical regulations of the National University of Ireland (Galway, Ireland). MSCs were isolated from the bone marrow of 8-12 weeks old male Sprague Dawley rats (Harlan Laboratories, Oxfordshire, UK) as previously described [14-16]. Briefly, after euthanasia, marrow was flushed from femoral and tibial compartments with complete rMSC growth medium, which consisted of 44.5\% $\alpha$-MEM (Gibco, Invitrogen, Carlsbad, CA, USA) and 44.5\% F12-Ham (Gibco), supplemented with 10\% FBS (Gibco) and $100 \mathrm{U} / \mathrm{ml}$ penicillin-G and $100 \mu \mathrm{g} / \mathrm{ml}$ streptomycin sulphate (Gibco). Recovered suspensions were pooled, counted and plated at a density of $1.2 \times 10^{6}$ cells per $\mathrm{cm}^{2}$. Non-adherent cells were removed after 3 days and cells were re-fed with complete rMSC medium, with additional media changes every 3-4 days. After approximately 8 days or when cell cultures reached confluence, cells were detached with $0.25 \% \operatorname{trypsin}(\mathrm{w} /$ v) $/ 1 \mathrm{mM}$ EDTA solution and re-plated at $5.7 \times 10^{3}$ cells per $\mathrm{cm}^{2}$, with subsequent passage when they again reached confluence.

\section{MSC characterisation}

The ability to differentiate down the adipogenic, osteogenic and chondrogenic lineages, following isolation procedures described, was routinely tested in-house. According to criteria recommended by the International Society for Cellular Therapy (ISCT), an MSC deemed acceptable for laboratory based investigations and preclinical studies is defined by its adherence to plastic, differentiation capacity and cell surface markers (CD105, CD73, CD90 positive and CD34, CD45, CD14 or CD11b, CD79a or CD19 and HLA-DR negative). Isolated MSCs were routinely characterised in-house by flow cytometry for their cell surface markers, as previously described $[10,11]$.

\section{MSC transduction and gfp reporter gene detection}

MSCs were seeded in 6 -well plates at $1 \times 10^{5}$ cells per well, grown overnight and transduced with lentiviral vectors in a minimal volume of medium. MSCs were harvested for analysis, at the earliest, $96 \mathrm{~h}$ post-transduction. For the 28-day transgene analysis experiments, cells were harvested at $7 \mathrm{~d}$ intervals, at which point each cell population per well was split, using one half to maintain the cells in culture and the other for GFP expression analysis (see below). For assessment of transgene silencing, transduced cell populations were cultured in medium containing the histone deacetylase (HDAC) inhibitor, trichostatin A (TSA; $100 \mathrm{nM}$ ) and/or the DNA methyltransferase inhibitor 5-azacytidine (5aza-c; $5 \mu \mathrm{M}$ ) for the 28-day period, harvesting at $7 \mathrm{~d}$ intervals. MSCs were harvested by trypsinisation, fixed in $4 \%$ paraformaldehyde and resuspended in PBS. Percentage GFP-positive cells and their mean fluorescence intensity (MFI) was determined using Guava Express Plus analysis on a GuavaEasyCyte ${ }^{\mathrm{TM}}$ flow cytometer (Guava Technologies, Millipore, Billerica, MA, USA). Total GFP was calculated by multiplication of the percentage GFP positive cells by the MFI.

\section{Therapeutic transgene expression analysis}

Rat MSCs were transduced by incubation with lentiviral vectors at a multiplicity of infection (MOI) of 100 for 18 hours. Transgene expression was measured $72 \mathrm{~h}$ post-transduction by immunofluorescent staining and Western blot analysis (Figure S1 in Additional file 1).

\section{In vitro ischaemia treatments}

To mimic the in vivo scenario of ischaemia, MSC were exposed to conditions of hypoxia $\left(\mathrm{O}_{2}\right.$ at $0.5 \%$ plus complete DMEM), ischaemia $\left(\mathrm{O}_{2}\right.$ at $0.5 \%$ in serum and glucose free DMEM) and complete $\mathrm{O}_{2}$ and glucose deprivation by inhibition of glycolysis (ischaemia +2deoxyglucose) in an in vivo 400 hypoxia chamber (Ruskinn Technologies, UK). 2-deoxyglucose (2DG) is a 
glycolytic inhibitor, which prevents hexokinase phosphorylation of glucose. Addition of this inhibitor provided an in vitro model of complete glucose deprivation. For these experiments, MSCs were seeded and transduced under normal culture conditions until $72 \mathrm{~h}$ post transduction when cells were optimally expressing transgene. The appropriate media for each condition (hypoxia, ischaemia, ischaemia $+2 \mathrm{DG}$ ) was placed in the hypoxia chamber for a minimum of 3 hours to deplete the oxygen levels to the required 0.5\%. Depleted media was added to MSCs, which were treated with the appropriate conditions for the required period of time.

\section{Assessment of viability and apoptosis}

MSC viability was determined by standard MTT assay as described previously [17]. Apoptosis levels were assessed by identification of apoptotic nuclei by DAPI staining of MSCs. Percentage apoptotic cells was determined in a semi-quantitative manner by counting numbers of apoptotic nuclei per field of ten random images. Caspase-3 activation was also examined using AcDEVD-AFC substrate (Biomol, Enzo Life Sciences, PA, USA). Staurosporine (STS - at $500 \mathrm{nM}$ for $12 \mathrm{~h}$ ) was used as a positive control for caspase activation.

\section{Adipogenesis differentiation assay}

MSCs (both transduced and non-transduced) were seeded at $2 \times 10^{5}$ cell per well in 6-well plates. Once cells had reached confluence, adipogenic differentiation was induced by three $72 \mathrm{~h}$ cycles of adipogenic induction media ( $1 \mu \mathrm{M}$ dexamethasone, $10 \mu \mathrm{g} / \mathrm{ml}$ insulin, 200 $\mu \mathrm{M}$ indomethacin, $500 \mu \mathrm{M}$ 3-isobutyl-1-methylXanthine, $100 \mathrm{U} / \mathrm{ml}$ penicillin, $100 \mu \mathrm{g} / \mathrm{ml}$ streptomycin, $10 \%$ FBS and 5\% rabbit serum in high-glucose DMEM). Following each round of induction, cells were maintained in maintenance medium for $24 \mathrm{~h}(10 \mu \mathrm{g} / \mathrm{ml}$ insulin in complete high glucose medium), and for 5-7 days after final induction. Cells were fixed in $10 \%$ formalin and differentiated cells were identified by Oil Red O stain for lipid vacuoles. Images of 10 random fields for each well were acquired and differentiated cells containing stained lipid vacuoles per microscope field were counted. Oil Red O stain was also quantified by extraction of the stain into $99 \%$ isopropanol and absorbance measurement on a Wallac plate reader at $490 \mathrm{~nm}$. Noninduced MSCs, maintained in normal growth medium, were included as negative controls for the adipogenesis assay.

\section{Statistical analysis}

Data are presented as mean \pm standard deviation $(n=3)$ of three independent experiments. Statistical analyses were carried out on data sets using SigmaStat for Windows, version 3.5. One-way analysis of variance
(ANOVA) was used to determine statistical significance between groups, followed by multiple paired comparisons for normally distributed data (Tukey Test). Nonnormally distributed data were analysed by ANOVA on ranks using either Dunn's Test or Kruskal-Wallis. Paired t-tests were used for pairwise comparisons. Values of $\mathrm{p}<0.05$ were considered statistically significant $\left({ }^{*} \mathrm{p}<\right.$ $\left.0.05,{ }^{* * *} \mathrm{p}<0.001\right)$.

\section{Results}

\section{Lentiviral vector efficiency in rat MSCs}

Of the vectors evaluated, it was determined that the second generation VSV-G pWPT-EF1- $\alpha$-GFP-W was the most efficient at rat MSC transduction. At MOI 100, this vector gave transduction efficiencies of $90-98 \%$ at 7 , 14, 21 and 28 days respectively (Figure 1A), and total GFP values of over 75,000 at all time points (Figure 1B). This vector consistently mediated high level, sustained GFP transgene expression levels with no significant reduction throughout the time frame analysed. This was in contrast to the rHIV-cPPT-CMV-GFP-W and rHIVPPT-PGK-GFP-W lentiviral vectors, which were tested in parallel, and consistently gave percentage GFP positives of $1-5 \%$ and $35-40 \%$ (Figure $1 \mathrm{~A}$ ), and total GFP values of 4,552-186 and 28,866-15,806 (Figure 1B) respectively. These significantly lower values were observed at all MOIs tested (data not shown).

\section{Lentiviral vector transgene silencing in rat MSCs}

Silencing of vector transgene is an important factor to consider where long term stable expression of transgene is required in target cells. Here, the reactivation potential of reporter transgene was assessed over a 28-day time period, by treatment of transduced cells with the HDAC inhibitor TSA, and the DNA methyltransferase inhibitor 5 -aza-c. The existence of vector silencing was indicated by an increase in reporter gene expression detectable by FACS, following release of promoter function after drug treatment (Figure 2). TSA and 5-aza-c treatment of rHIV-cPPT-CMV-GFP-W transduced rMSCs resulted in significant increases of GFP positive cells at an MOI of 100 , indicating that reporter transgene may have been reactivated upon exposure to the methylation and deacetylation inhibitors (Figure 2A). TSA exposure increased the percentage of GFP positive cells at all time points, these increases were significant at day 14 and day 28 ( $\mathrm{p}<$ 0.05 ). At all measured time points, treatment with 5-azac significantly increased GFP transgene expressing cell numbers compared to non-treated control cells, with the largest observed increases at day 14 and day 21 ( $\mathrm{p}<$ 0.001). Although there were increases in rHIV-PPTPGK-GFP-W vector transduction levels (Figure 2B), these were not significant compared to controls. Likewise, there were no apparent changes in transgene 


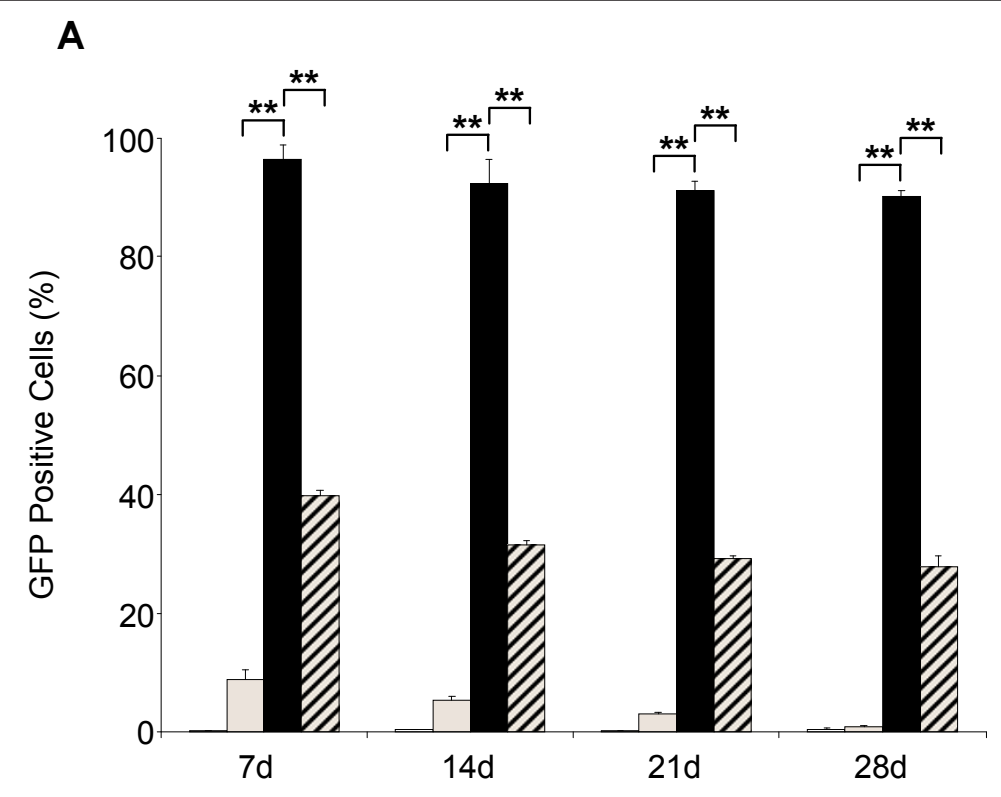

B

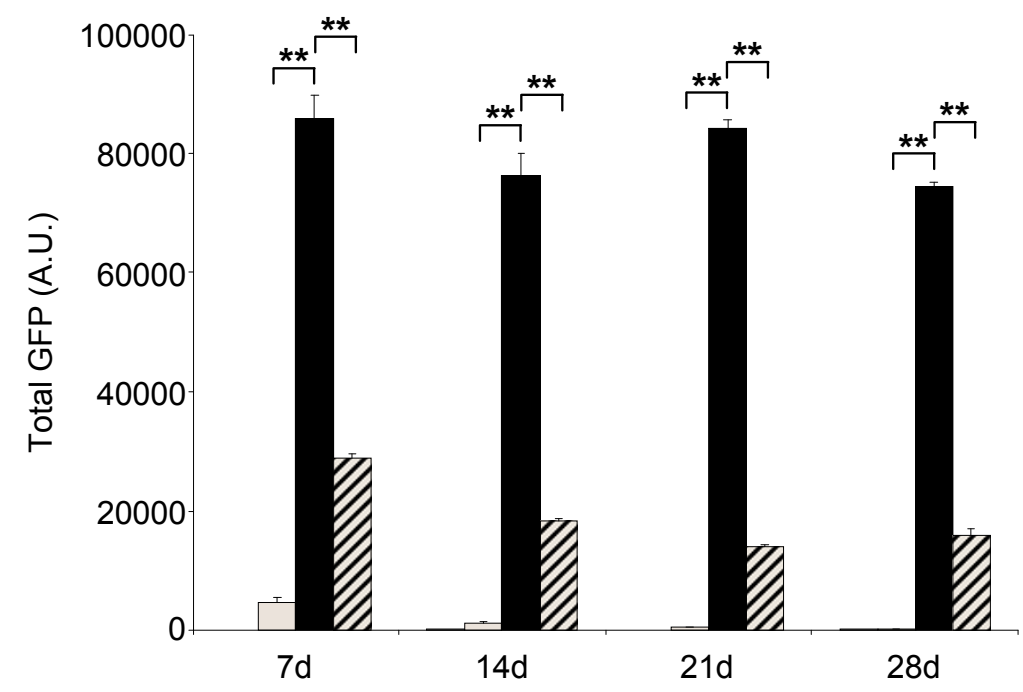

$\square$ Non-transduced $\square$ CMV promoter $\quad$ EFl-a promoter $\mathbb{Z}$ PGK promoter

Figure 1 Lentivirus vector efficiency in rat MSC. (A) Percentage GFP positive cells and (B) total GFP (mean fluorescent intensity $X \%$ GFP positive cells) in MSCs after transduction with the described lentivirus vectors over a 28 day period with no selection methods at MOI 100 . Data are shown as mean $\pm \mathrm{SD}(n=3)$ of three independent experiments. ${ }^{*} \mathrm{p}<0.05,{ }^{* *} \mathrm{p}<0.001$ rHIV-pWPT-Ef1-a-GFP-W vector vs. PGK and CMV promoter-containing vectors. 


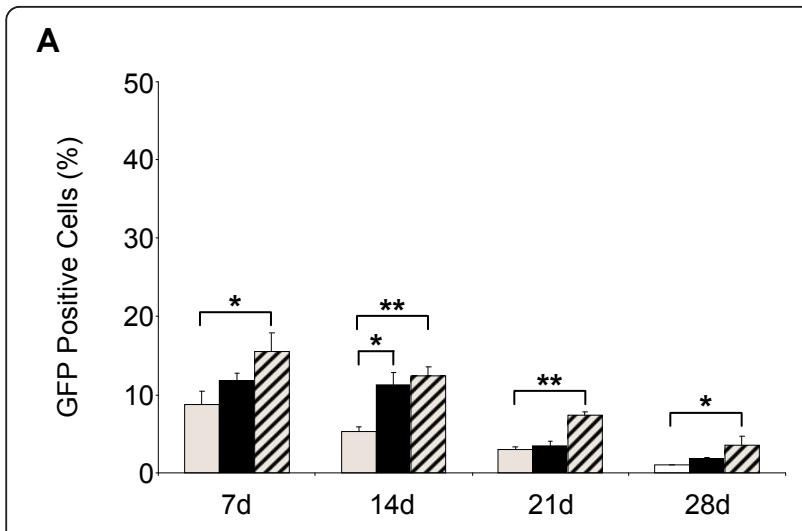

B

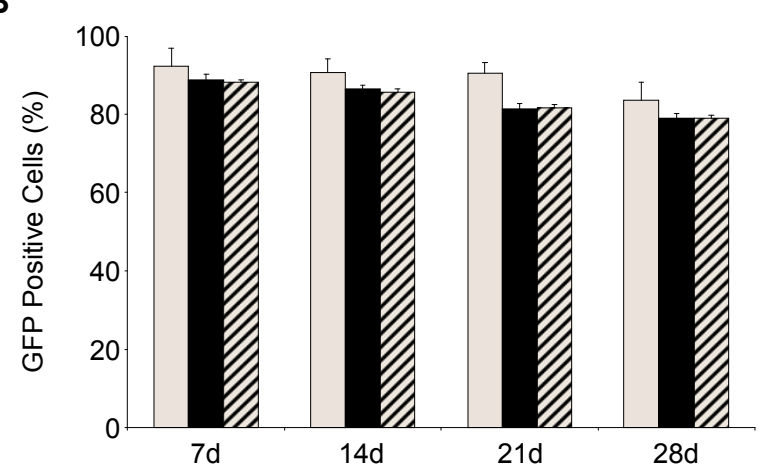

C

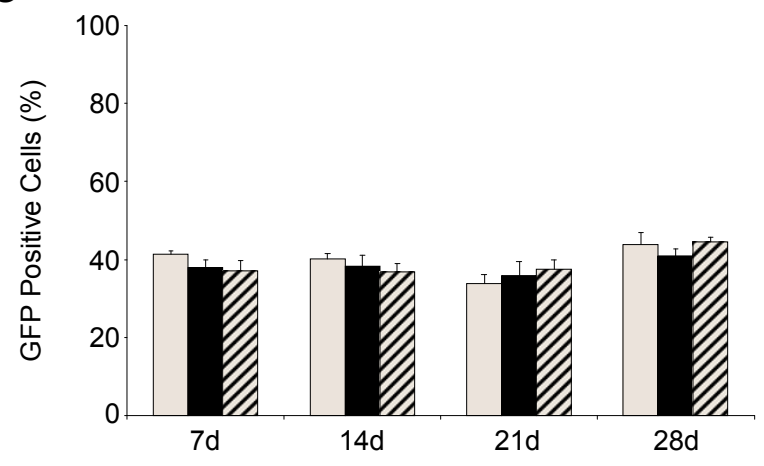

$$
\text { Vehicle } \square \text { TSA } \quad \text { T-aza-c }
$$

Figure 2 TSA/5-AZA-C treatment on GFP transgene expression in lentiviral vector modified rat MSCs over 28d. (A) rHIV-CPPTCMV-GFP-W transduced rMSC at MOI 100. (B) rHIV-pWPT-EF1-a-GFPW transduced rMSC at MOI 100. (C) rHIV-PPT-PGK-GFP-W transduced rMSC at MOI 100. Data are shown as mean \pm SD $(n=3)$ of three independent experiments. ${ }^{*} p<0.05,{ }^{* *} p<0.001$ vs. no drug.

expression levels of rHIV-pWPT-EF1- $\alpha$-GFP-W transduced MSCs (Figure 2C), which suggests that transgene silencing is not a significant issue with respect to these particular constructs. Similar results were observed at other MOIs tested (data not shown).
Transduction with second generation pWPT-EF1- $\alpha$-GFP-W lentiviral vector does not affect viability or differentiation potential

Toxicity of the vectors, following transduction was analysed by measurement of cell viability, using MTT assay (Figure 3A). No significant adverse effect on cell viability was apparent when compared to non-transduced control cells. Increase of viral dose resulted in an expected increase in cell death, but these numbers always remained low, with a percentage cell death of only $~ 5 \%$ being seen at the maximal MOI of 100 .

MSC differentiation capacity was determined by lipid vacuole formation after a 21-day adipogenesis assay (Figure $3 \mathrm{~B}, \mathrm{C}, \mathrm{D})$. Under normal culture conditions, MSCs transduced with the rHIV-pWPT vector underwent adipogenesis at the same efficiency as control non-transduced MSCs (Figure 3B,C,D). Inhibitory effects on rat MSC adipogenic differentiation ability were not observed, either in terms of numbers of differentiated cells (Figure 3C) or amount of lipid vacuoles measured spectrophotometrically (Figure 3D).

\section{Factors affecting transgene expression in pWPT-EF1- $\alpha$ - GFP-W modified MSCs}

A significant dose response, with increasing virus particle concentration from MOI 1 to MOI 100 ( $\mathrm{p}<0.05)$, was achieved in rat MSCs transduced with rHIVpWPT-EF1- $\alpha$-GFP-W vector, as expected. The percentage of GFP-positive MSCs increased from $\sim 17 \%$ at MOI 1 to $\sim 98 \%$ at MOI 100 (Figure 4A). The effect of MSC passage number on pWPT-Ef1- $\alpha$-GFP-W transduction efficiency and transgene expression was analysed by transduction of rat MSCs of early and late passage numbers and determination of numbers of transduced cells by FACS analysis. Here, a difference in transgene expression levels between the passage numbers was apparent (Figure 4B). At both MOIs measured, there were significant differences between early and late MSC passage numbers. At MOI 50, there was a decrease of approximately $15 \%$ in P5 and 13\% in P4 MSCs compared to P1 MSC populations ( $\mathrm{p}<0.05)$. At the higher MOI of 100, a similar decrease in percentage transduced cells with increasing passage number was observed, however this was only significant between P1 and P5 MSC populations, with a reduction of approximately $8 \%(\mathrm{p}<0.05)$. A direct comparison was made between rat and human MSCs, which had been transduced at MOI 50 and MOI 100 by pWPT-EF1- $\alpha$-GFP$\mathrm{W}$ lentiviral vector (Figure 4C). There was no significant difference found between transduction levels in human and rat MSCs, at either MOI tested. The effect of cryopreservation on transduced rMSC populations was also examined (Figure 4D), where no negative impact on transgene GFP expression was detected. 
A

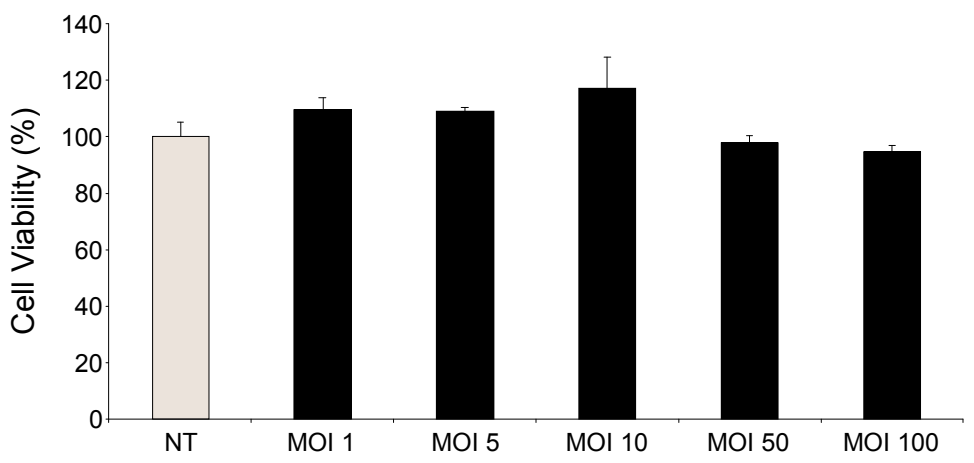

B
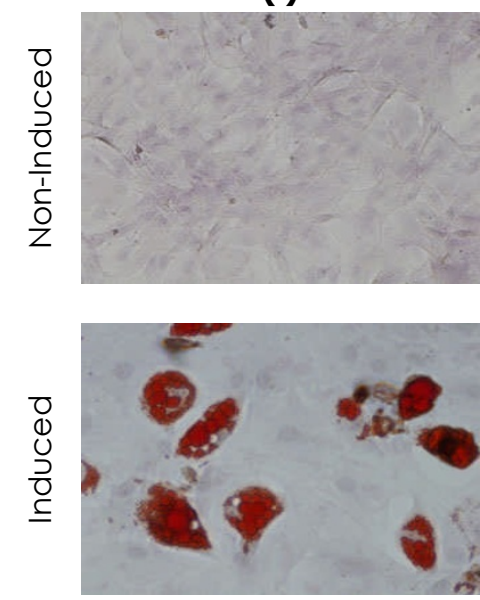

(ii)
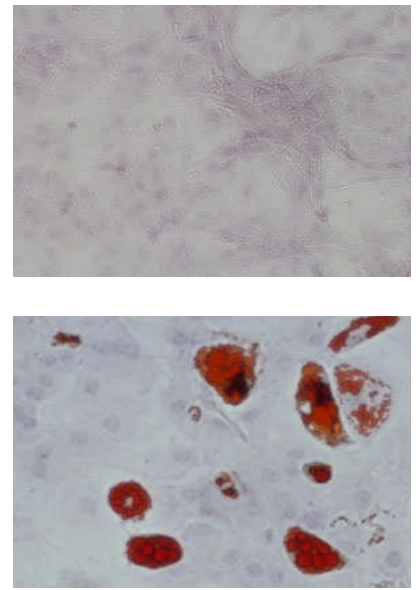

C

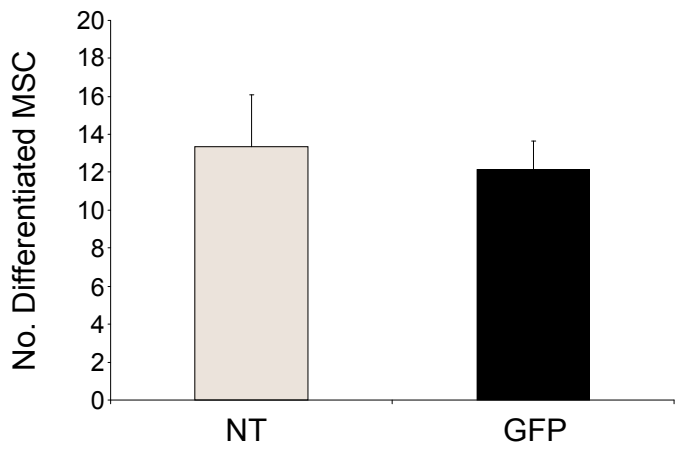

D

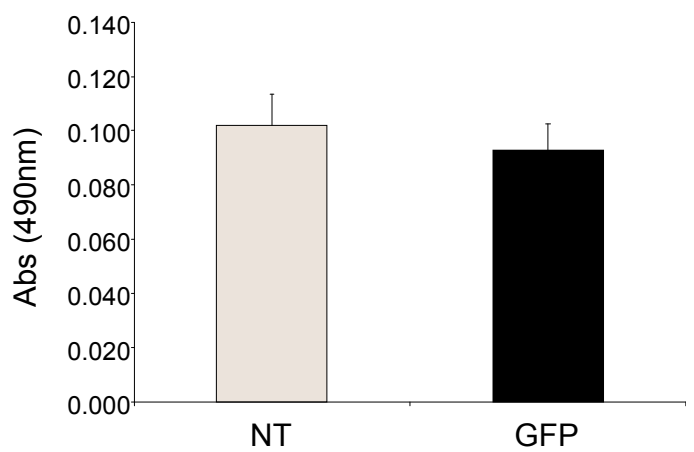

Figure 3 rHIV-pWPT-EF1-a-GFP-W lentiviral vector modification does not affect msc viability or differentiation potential. (A) Evaluation of rHIV-pWPT-EF1-a-GFP-W vector toxicity on rMSC viability by MTT assay. (B) Representative images (magnification 20X) of non-induced control MSCs and MSCs induced towards the adipogenic pathway (i) non-transduced, (ii) rHIV-pWPT-EF1-a-GFP-W transduced (MOI 100) MSCs. (C) Oil red $\mathrm{O}$ positive cells per microscope field (number of differentiated cells). (D) Oil red O quantitation. Data are presented as mean \pm SD ( $n=5$ ) or as representative images of three independent experiments. 


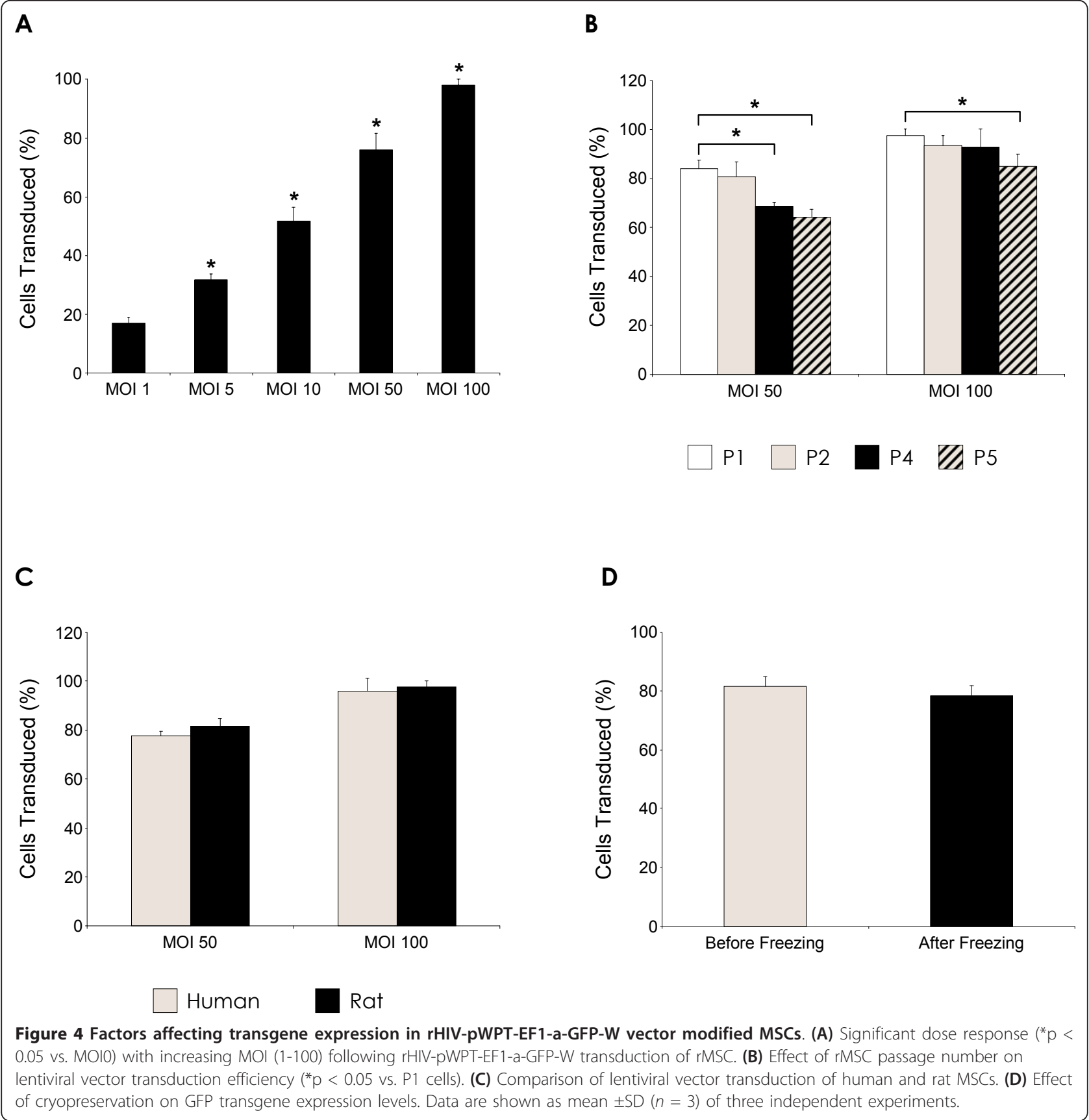

\section{Hypoxia}

MSC viability was detected by MTT assay after exposure to hypoxic conditions (Figure 5A). MSC viability decreased with increasing hypoxia exposure time, from approximately $97 \%$ at 12 hours of hypoxia to $60 \%$ at 96 h. Transduction with the HSP70 lentiviral vector, and consequent HSP70 over-expression, significantly increased percentage viability at both $72 \mathrm{~h}$ and $96 \mathrm{~h}$ of hypoxia compared to non-transduced and GFP control MSCs $(\mathrm{p}<0.05)$. Catalase and SOD over-expression did not increase viability to the same extent as HSP70, although at $48 \mathrm{~h}$ SOD1-MSCs were more viable than controls $(\mathrm{p}<0.05)$. Control GFP MSC percentage viability remained similar to that of non-transduced MSCs, proving that any observed effects were as a result of transgene over-expression and not due to the lentiviral vector itself.

The effect of HSP70 over-expression on hypoxiainduced apoptosis was also assessed. Classical signs of apoptotic cell death were visible with respect to nuclear 
A

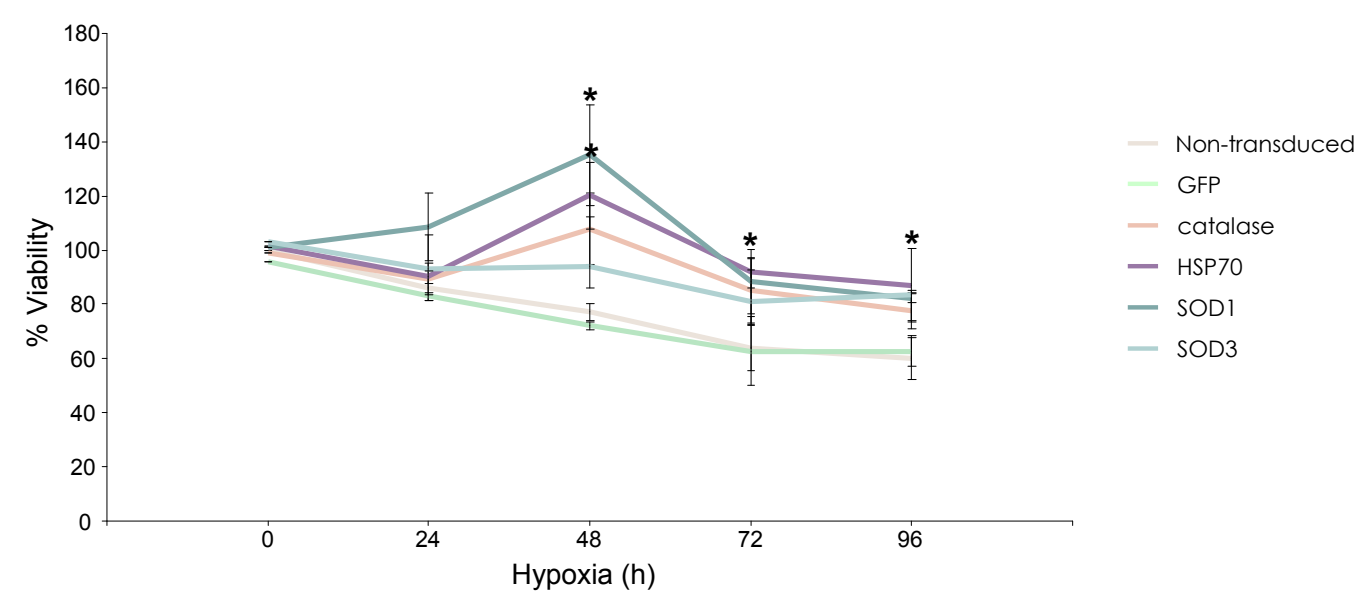

B

NT

GFP

HSP70
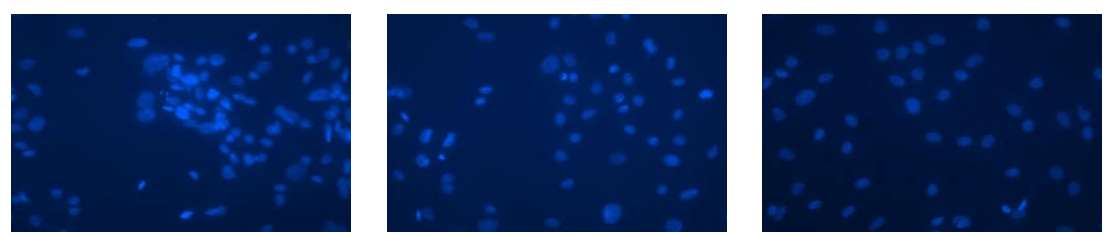

C

D

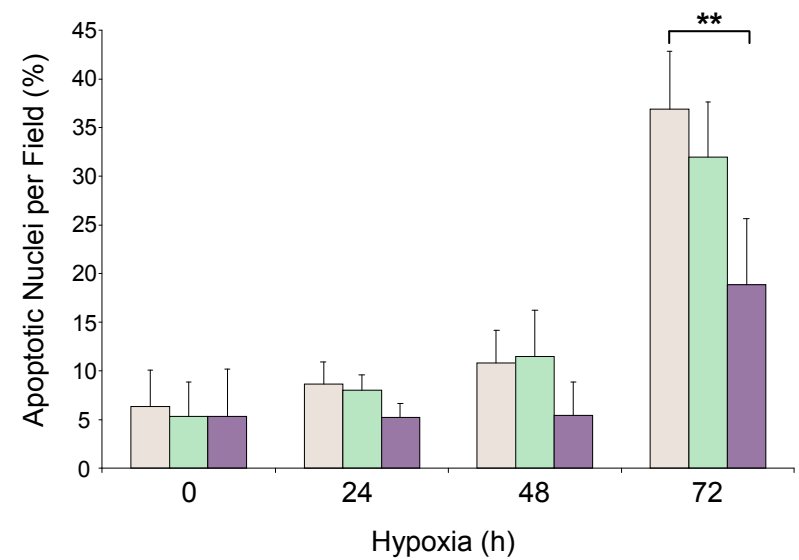

Non-transduced

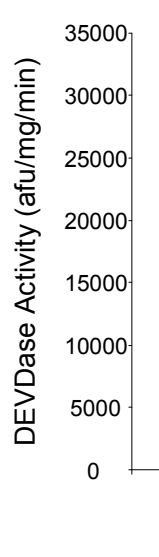

GFP

HSP70

Figure 5 Enhanced MSC survival by lentiviral vector modification in hypoxia. (A) Percentage rMSC viability as determined by MTT assay after hypoxia exposure ( ${ }^{*} \mathrm{p}<0.05$ HSP70-MSCs and SOD1-MSCs vs. non-transduced MSCs). (B) DAPI staining of MSCs after $72 \mathrm{~h}$ hypoxia. (C) Percentage apoptotic nuclei per microscope field $(n=10)$ at $72 \mathrm{~h}$ hypoxia $(* * p<0.001$ HSP70 MSCs vs. non-transduced MSCs). (D) Caspase-3 activity in MSC after $48 \mathrm{~h}$ and $72 \mathrm{~h}$ hypoxia ( ${ }^{*} \mathrm{p}<0.05$ HSP70-MSCs vs. non-transduced MSC). Data are shown as mean \pm SD ( $\left.n=3\right)$ or as representative images of three independent experiments. 
morphology, which included misshapen or "beanshaped" nuclear membranes, intense fluorescence indicative of nuclear condensation, nuclear fragmentation and disassembly into apoptotic bodies (Figure 5B). The percentage of apoptotic cells was also calculated from these images (Figure 5C). A significant increase in apoptotic nuclei was evident after $72 \mathrm{~h}$ of hypoxia, at which point numbers were significantly reduced in the HSP70 group compared to controls $(\mathrm{p}<0.001)$. The morphological changes indicative of apoptosis were confirmed by caspase activity measurement at 48 and 72 hours of hypoxia (Figure 5D). At $48 \mathrm{~h}$ there was no apparent increase in caspase activity in either the non-transduced or transduced MSC groups. At $72 \mathrm{~h}$, there was a significant increase in caspase activity across the groups, which was significantly reduced in transduced MSCs that were over-expressing HSP70, compared to control MSCs $(\mathrm{p}<0.05)$.

\section{Ischaemia}

Not unexpectedly, MSCs were more sensitive to conditions of ischaemia than hypoxia (Figure 6A). After 12 hours of ischaemia, cell viability had decreased to approximately $70 \%$, falling to $20 \%$ by 96 h. Exogenous expression of HSP70 produced a significantly higher percentage of viable MSCs at several time points compared to control groups at $96 \mathrm{~h}(\mathrm{p}<0.05)$. No significant increases in viability were measured for catalase or SOD modified MSCs compared to controls at any time point. An increase in apoptotic nuclei number was apparent as ischaemia exposure time increased (Figure 6B). Fewer apoptotic nuclei were present in the HSP70 group at $48 \mathrm{~h}$ and $72 \mathrm{~h}$ (Figure 6C), which was significant compared with controls $(\mathrm{p}<0.001)$. Increased caspase-3 activity was observed across all MSC groups exposed to ischaemia at the $48 \mathrm{~h}$ and $72 \mathrm{~h}$ time points examined (Figure 6D). Caspase activity was significantly decreased in HSP70-MSCs compared to non-transduced and GFP-MSC controls ( $\mathrm{p}<0.05)$.

\section{Ischaemia and 2-deoxyglucose (2DG)}

To mimic the in vivo scenario of ischaemia where cells may not be able to use glycolysis for ATP level maintenance, MSCs were treated with $1 \mathrm{mM} 2 \mathrm{DG}$ in addition to the conditions of ischaemia previously described. Addition of 2DG exacerbated the observed effects on MSC survival in terms of viability and apoptosis. After 12 hours of treatment, viability of unmodified MSCs had decreased below $40 \%$, falling to less than $10 \%$ at the latest time point examined (Figure 7A).

At the early time points of 12 and 24 hours, the HSP70-MSC group displayed significantly increased viability, compared to controls at $24 \mathrm{~h}(\mathrm{p}<0.001)$. There was no apparent effect of exogenous HSP70 expression at any later time points. Analysis of nuclear morphology showed that increased numbers of apoptotic cells were present with ischaemia $+2 \mathrm{DG}$ exposure compared to the previous treatments (Figure 7B). Numbers of apoptotic nuclei were significantly reduced in the HSP70 group compared to controls at $48 \mathrm{~h}(\mathrm{p}<0.05)$ and $72 \mathrm{~h}$ $(\mathrm{p}<0.001)$ (Figure 7C). Caspase 3 activity levels were stimulated by ischaemia 2DG treatment and peaked at $48 \mathrm{~h}$, after which activity levels dropped by almost half (Figure 7D). At both time points examined, induced HSP70 over-expression did not offer significant protection against caspase-3-dependent apoptosis.

\section{Hypoxia, ischaemia and MSC differentiation}

The effect of ischaemic stress on MSC differentiation capacity was determined by lipid vacuole formation after a 21-day adipogenesis assay. Differentiated cells were identified by Oil Red $\mathrm{O}$ staining for lipid vacuoles (Figure 8A). MSCs that were exposed to in vitro models of ischaemia produced fewer lipid vesicles compared to normoxic MSCs. However, HSP70 over-expression reduced this inhibitory effect of oxygen, serum and glucose deprivation on MSC adipogenesis. This was in terms of numbers of differentiated cells (Figure 8B) and the amount of lipid vacuoles measured (Figure $8 \mathrm{C}$ ), compared with controls $(\mathrm{p}<0.05, \mathrm{p}<0.001)$.

\section{Discussion}

\section{Genetic modification of MSCs}

Numerous studies have utilised genetically engineered MSCs, which have been modified by various gene therapy vectors including adenovirus [18,19], AAV [20], non-viral vectors $[21,22]$, and lentivirus [23,24]. Initial vector transduction efficiency and optimisation studies are the foundation of future in vivo experiments and therefore the efficiency of vector transduction of MSCs determines whether a particular preclinical model is worth pursuing. In the present study, we compare three different lentiviral vector types; two second generation vectors containing either the EF1- $\alpha$ or CMV promoter and a third generation vector with GFP transgene expression under control of the PGK promoter. In the second generation lentiviral vector system, five of the nine HIV-1 genes are eliminated, retaining genes for virion structural proteins and enzymes (gag/pol) and genes relating to transcriptional and post-transcriptional functions (tat and rev). These vectors are produced with a 3 plasmid packaging system. The latest third generation vectors have further HIV-1 genes deleted leaving only gag, pol and rev and are produced using a four-plasmid set. This vector generation has been designed using a chimeric LTR (long terminal repeat) ensuring transcription in the absence of tat. As a result, this vector system possesses a higher safety profile and is more suitable for 


\section{A}

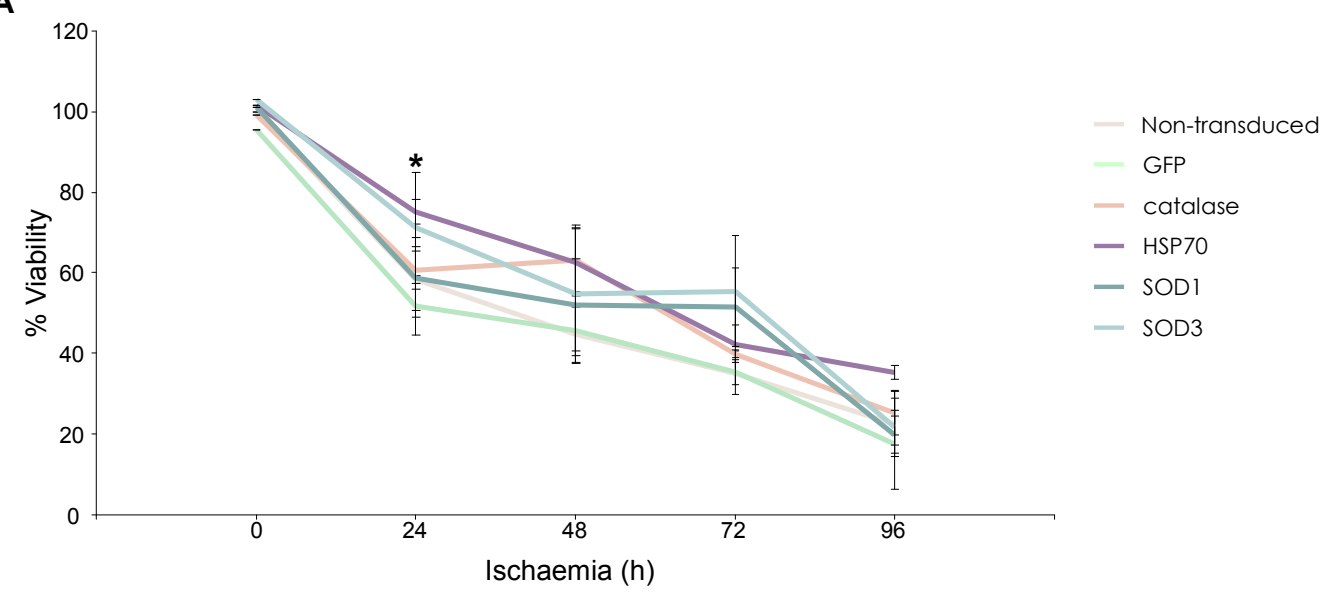

B

NT

GFP

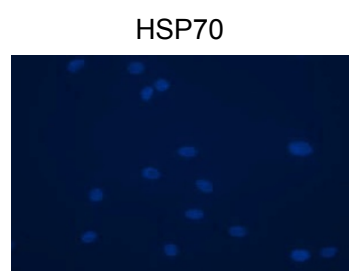

C
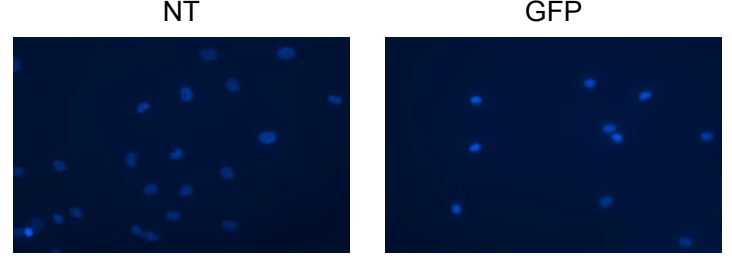

D
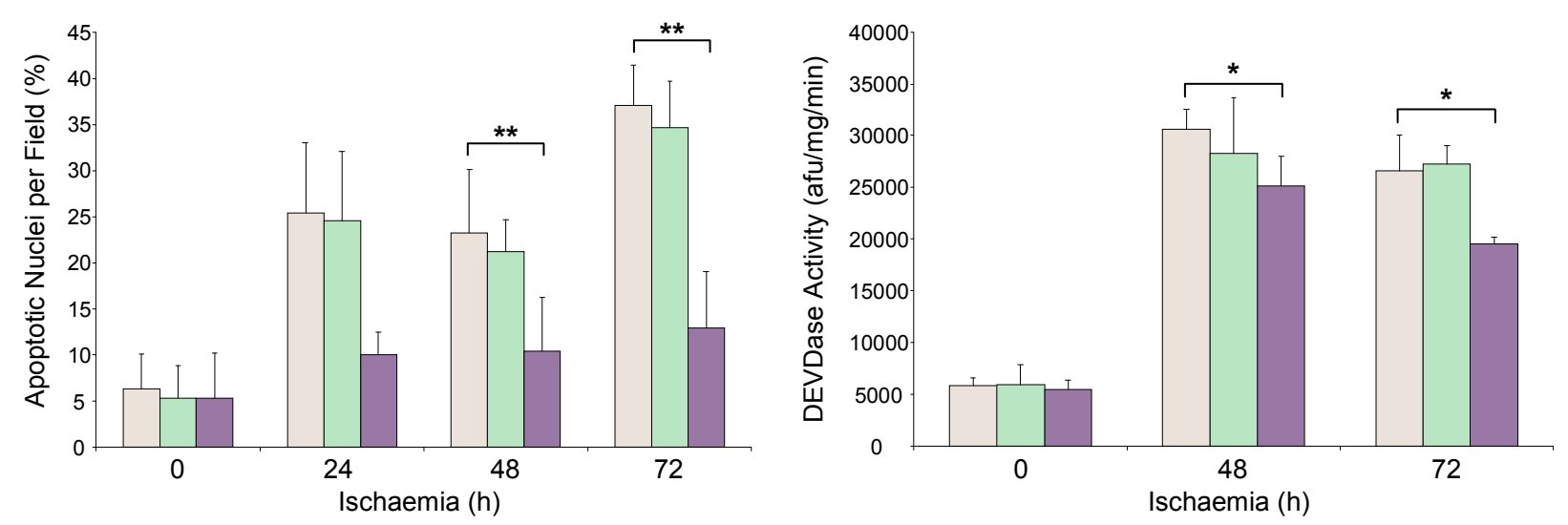

Non-transduced

GFP

HSP70

Figure 6 Enhanced MSC survival by lentiviral vector modification in ischaemia. (A) Percentage rMSC viability as determined by MTT assay after ischaemia exposure ${ }^{*} \mathrm{p}<0.05$ HSP70-MSCs vs. non-transduced MSC). (B) DAPI staining of MSCs after $72 \mathrm{~h}$ ischaemia. (C) Percentage apoptotic nuclei per microscope field $(n=10)\left({ }^{* *} \mathrm{p}<0.001\right.$ HSP70-MSCs vs. non-transduced MSCs at $48 \mathrm{~h}$ and $72 \mathrm{~h}$ ischaemia). (D) Caspase-3 activity in rMSC after $48 \mathrm{~h}$ and $72 \mathrm{~h}$ ischaemia ( ${ }^{*} \mathrm{p}<0.05$ HSP70-MSCs vs. non-transduced MSCs). Data are shown as mean \pm SD $(n=3)$ or as representative images of three independent experiments. 
A

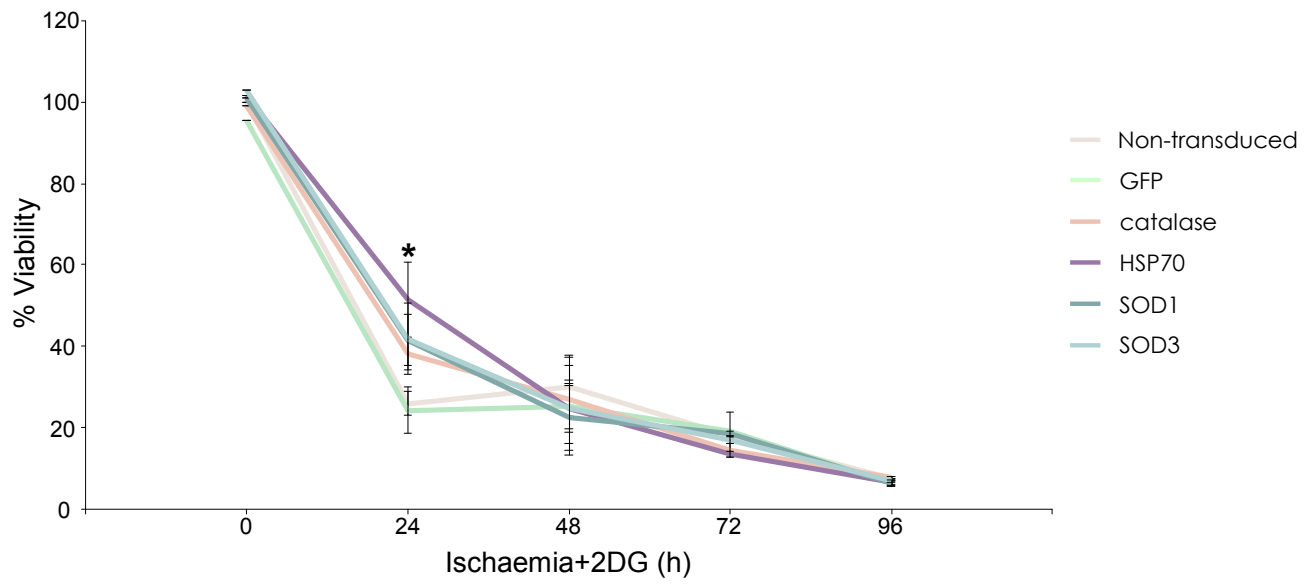

B

NT
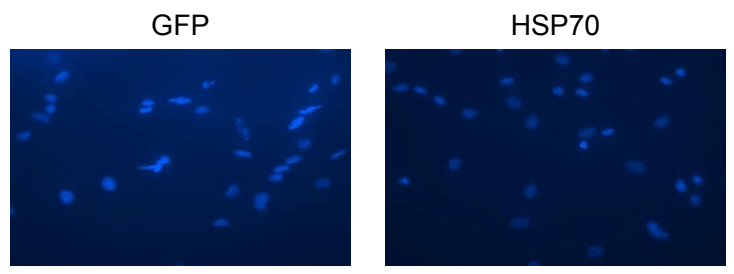

C

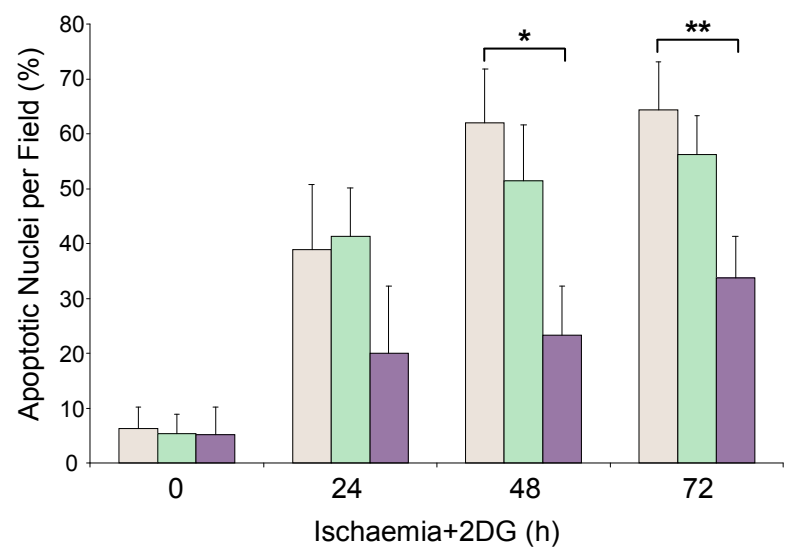

D

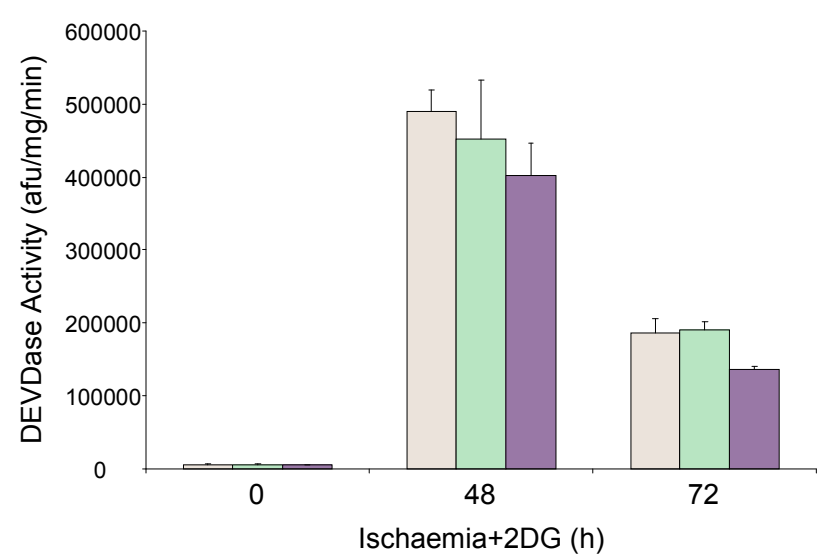

HSP70

Figure 7 Enhanced MSC survival by lentiviral vector modification in ischaemia with glycolysis inhibition - complete glucose deprivation. (A) Percentage rMSC viability as determined by MTT assay after ischaemia with 2DG exposure $\left({ }^{*} p<0.05\right.$ HSP70-MSC vs. nontransduced MSC). (B) DAPI staining of MSCs after $72 \mathrm{~h}$ ischaemia $+2 \mathrm{DG}$. (C) Percentage apoptotic nuclei per microscope field $(n=10)\left({ }^{*} \mathrm{p}<\right.$ $0.05,{ }^{* *} \mathrm{p}<0.001$ HSP70-MSCs vs. non-transduced MSC). (D) Caspase-3 activity in MSC after $48 \mathrm{~h}$ and $72 \mathrm{~h}$ ischaemia $+2 \mathrm{DG}\left({ }^{*} \mathrm{p}<0.05 \mathrm{HSP70}-\right.$ MSCs vs. non-transduced MSC). Data are shown as mean $\pm \mathrm{SD}(n=3)$ or as representative images of three independent experiments. 


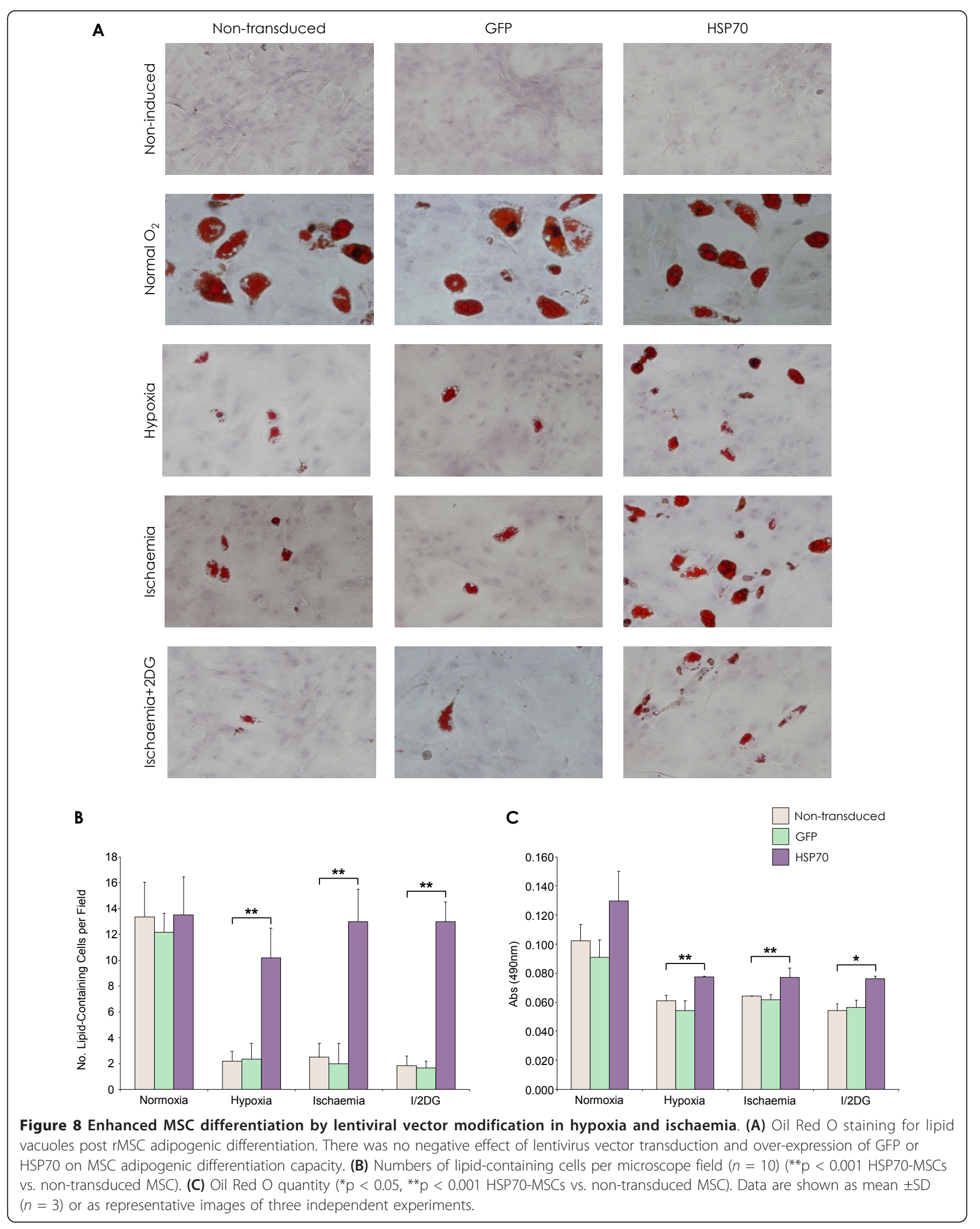


clinical applications. Vector generation and promoter type will undoubtedly affect transduction levels - low or short-lived transgene expression levels, cytotoxicity or transgene silencing may prompt the choice of an alternative vector type or model. Consequently, a full investigation into the ex vivo transduction potential of MSCs derived from the same species is essential. This series of experiments set out to assess and optimise lentiviral vector transduction efficiency in rat MSCs, and also to examine any functional effect of genetic modification in an in vitro model of ischaemia.

Gene silencing can present problems when using gene delivery as certain vectors and promoters have been shown to be susceptible to transcriptional silencing in particular host cell types. It is widely accepted that retroviruses are silenced in stem cells [25-28], however, it remains controversial as to whether HIV-1-based SIN lentiviral vectors are also subjected to the same effects [29-32]. There have been several reports that SIN lentiviral vectors can be silenced to some degree in embryonic stem (ES) cells [29] and primary murine hematopoietic stem cells (HSCs) [32], with varying silencing rates but thus far, there have been no definitive reports of lentiviral vector transgene silencing in mesenchymal stem cells. This concept of vector transgene silencing is of considerable importance where stable long-term gene expression is required. Although the present study is not a conclusive demonstration that promoter/transgene silencing or inactivation does not occur, the experimental results suggest that it is not a major factor to be considered, with respect to rat MSC transduction by the second generation VSV-G rHIVpWPT-EF1- $\alpha$-GFP-W lentiviral vector. Upon consideration of the collective data from the vector and silencing experiments, it is clear that the second generation VSV$G$ pseudotyped, EF1- $\alpha$ promoter driven construct, rHIV-pWPT-EF1- $\alpha$-GFP-W, is the vector of choice for the successful and efficient in vitro transduction of MSCs. Modification with this particular vector facilitated sustained, persistent and high-level transgene expression in target rat MSCs, possibly due to various factors, the most likely being promoter type. Several in vitro studies have compared promoters in similar lentiviral vector constructs and have determined the Ef1- $\alpha$ promoter to be superior to other promoters tested and mediate high transgene expression levels [33]. This finding is of particular relevance to the use of MSCs for ex vivo transplantation in various preclinical models, where long term gene expression is required. To this end, this second generation VSV-G rHIV-pWPT-EF1- $\alpha$ GFP-W lentiviral vector was chosen for all further MSC modification in this study.

In addition to assessment of transduction efficiency, we subsequently sought to examine the survival and differentiation potential of MSCs modified with this vector. As expected, a dose-response effect was achieved by transducing cells with increasing MOI, with levels approaching $100 \%$ transduction being achieved at MOI 100. In addition, we examined any toxic effect that transduction with this vector may have on cell viability and found that lentiviral vector modification of rat MSCs had no significant negative effects. Levels of cell death did not surpass $\sim 5 \%$ of total cell population when transduced with the rHIV-pWPT-EF1- $\alpha$-GFP-W vector at a high MOI of 100. This observed low level of cell death at the highest MOI measured may be in part due to a toxic effect of transgene rather than toxicity of the vector itself. GFP expression has previously been documented as being toxic in various cell types [34]. This lack of toxicity is significant and advantageous since not all vector types give the same results, for example gene transfer by adenovirus, lipid transfection and electroporation has been shown to be somewhat toxic to target cell populations [11]. It is noteworthy that, despite the integrative nature of lentivirus, modification with pWPT-EF1- $\alpha$-GFP-W vector does not have any deleterious effects on fundamental MSC differentiation function. There was no significant deterioration in differentiated cell numbers between non-transduced and transduced MSC populations, clearly demonstrating that MSC uptake of the VSV-G pseudotyped lentivirus, vector DNA integration and resultant transgene expression at a high MOI does not adversely affect MSC plasticity. The same pattern has been observed with various other transgenes (data not shown). Based on these data, it is likely that other differentiation pathways would be equally unaffected by lentiviral vector modification per se. Indeed, several studies have similarly observed that MSC transduction with lentivirus does not negatively affect osteogenic, chondrogenic or adipogenic differentiation, and that transgene expression is retained in the differentiated cells $[11,35]$. This fact further supports the clinical use of these genetically modified MSCs as gene delivery vehicles or as an enhanced therapeutic treatment for diseased and damaged tissue.

This study also investigated the effect of MSC transduction at subsequent passages and demonstrated that MSC passage number is important and affects vector transduction efficiency in terms of transgene expression levels. MSC transduction was more efficient at early passage numbers and was significantly decreased at later passage numbers. This is of importance for future experiments, as transduction at earlier passage numbers ultimately results in higher levels of transgene expression. It was also determined that cryopreservation of transduced MSCs had no negative effect on transgene expression levels. This is of particular relevance to preclinical and human trials, from a logistical perspective, 
as it is standard practice to harvest cells, transduce, expand and freeze, ready for therapeutic use. Other gene therapy vectors are unsuitable in this respect for MSC gene delivery, as with certain vectors e.g. adenovirus, continued and sustained transgene expression is not achievable [36]. As preclinical models are designed with the eventual scale-up to human trials in mind, it is necessary to examine the transduction of animal cells compared to cells of human origin. Here, no significant difference in transgene GFP levels were observed between human and rat cells, making it possible that preclinical studies arising from rat MSCs modified with this lentiviral vector could be translated into future human studies. These findings on rHIV-pWPT-Ef1- $\alpha-$ GFP-W MSC transduction are important for the possible future use of modified MSC in a clinical setting.

\section{In vitro ischaemia (oxygen, serum and glucose deprivation)}

In our investigation of lentivirus transduction of MSCs, we also sought to demonstrate a functional effect mediated by lentivirus vector-mediated genetic modification. For this, we primarily focused on an in vitro model of ischaemia, a condition of particular relevance to MSC transplantation, and several putative pro-survival genes. In our laboratory, Mylotte et al. demonstrated that MSCs tolerated in vitro conditions of hypoxia and ischaemia better than cardiomyocytes and were more vulnerable to ischaemia induced death rather than that of hypoxia [9]. This suggests that MSCs may possess the ability to survive short periods of hypoxia but not hypoxia with additional glucose and serum deprivation i.e. ischaemia. This survival capacity may however be amenable to improvement, by various gene therapy methods, thereby enhancing MSC therapeutic benefit.

In the present study, we assessed any benefit of induced therapeutic gene expression to MSCs, in an in vitro representation of the post-MI state, consisting of hypoxia and nutrient deprivation. Here, we found that MSCs tolerated hypoxia relatively well up to $72 \mathrm{~h}$, after which survival was adversely affected in terms of cell morphology, viability, cell numbers and apoptosis. At all time points measured, exposure to ischaemia significantly reduced MSC numbers and viability and significantly increased apoptosis. Addition of the glycolytic inhibitor, 2DG, has previously been used to mimic the inhibition of glycolysis that may occur during in vivo episodes of ischaemia $[37,38]$. Thus, 2DG was incorporated into the aforementioned ischaemia conditions representing a more severe model of ischaemia. Not unexpectedly, this most rigorous of all the injury models, significantly exacerbated MSC death levels compared to hypoxia and ischaemia, suggesting that glycolysis may support MSC survival in ischaemia.
All treatments triggered cell death by apoptosis in a time dependent manner, as identified by morphology (membrane blebbing, cell and nuclear shrinkage, chromatin condensation) and caspase- 3 activity. Hypoxia activated apoptotic cell death at $72 \mathrm{~h}$ whereas, under ischaemic conditions, apoptosis occurred earlier at $48 \mathrm{~h}$ as well as at $72 \mathrm{~h}$. Caspase activation detected in oxygen and serum-deprived MSCs correlated with time points where the highest cell death levels were observed, suggesting that MSC death is caspase dependent. These results were consistent with findings from other researchers that have observed MSCs to be relatively resistant to hypoxia to a certain point, but sensitive to ischaemia \pm 2 DG $[9,39]$. The models of ischaemia used in this study are well established [39-42] and combine the in vivo ischaemia components; hypoxia, serum deprivation and glucose deprivation. As higher levels of MSC death occurred in the models that incorporated serum and glucose deprivation as well as hypoxia, it is reasonable to conclude that MSCs are more vulnerable to apoptosis as a result of nutrient and survival growth factor withdrawal rather than hypoxia alone. With this in mind, rendering the MSC more resistant to apoptosis by any means would prove beneficial for the use of transplanted MSCs in the treatment of MI.

\section{Induced pro-survival Gene Over-Expression}

Following preliminary analysis of treatment effect, MSCs were transduced to over-express high levels of the prosurvival genes catalase, HSP27, HSP70, SOD1 and SOD3. The ability of the modified MSCs to tolerate the treatment conditions of conditions of hypoxia, ischaemia and ischaemia $+2 \mathrm{DG}$, compared with wild-type MSC was subsequently examined. Transduced MSC groups were observed to be more resistant to all treatments compared to control GFP and unmodified MSC groups in terms of survival. Cell survival was assessed initially by MTT viability assay so that the most effective gene could be focused on for further study. Of the genes tested, HSP70 over-expression significantly increased MSC viability in conditions of hypoxia, ischaemia and ischaemia +2 DG. In order to ascertain the manner of cell death occurring as a result of hypoxia and ischaemia, analysis of nuclear morphology and caspase induction was performed. The occurrence of apoptosis in response to in vitro models of hypoxia and ischaemia has been previously reported $[9,39]$. We found that apoptosis was induced by hypoxia at $72 \mathrm{~h}$ and not unexpectedly occurred earlier in MSCs exposed to ischaemia and ischaemia +2 DG. Most importantly, we demonstrated that the induced over-expression of HSP70 prevented MSC death by apoptosis. In response to hypoxia and ischaemia, there were significantly fewer apoptotic nuclei present and significantly decreased caspase- 3 
activity levels in the HSP70-MSCs compared to controls. These combined data demonstrate an increased MSC survival capacity mediated by lentivirus vector-mediated HSP70 over-expression, in a clinically relevant model of ischaemia.

\section{MSC differentiation and oxygen deprivation}

The effect of oxygen deprivation-induced stress on MSC differentiation was also assessed. Only the HSP70 gene was tested in this experiment as its over-expression had the most positive effect on MSC survival in previous experiments. Here, it was observed that none of the three oxygen deprivation treatment conditions completely diminished the ability of the MSCs to produce lipid vacuoles. This is consistent with reports that have showed MSCs retained the ability to differentiate into osteoblasts and adipocytes post in vitro hypoxia exposure [43-45]. A study by Lennon et al. demonstrated optimal MSC function at a reduced oxygen concentration of 5\% [46]; this is not entirely unexpected as these oxygen levels are similar to that of in vivo bone marrow [47]. Although differentiation capacity was not entirely eliminated, we observed it to be notably subdued, in that numbers and incidence of differentiated MSCs were significantly reduced, most obviously with exposure to ischaemia and ischaemia + 2DG. Interestingly, HSP70MSCs retained their functional differentiation capacity, as significantly increased numbers of differentiated cells were observed in this group. Neither did lentiviral vector-mediated HSP70 over-expression have any negative impact on MSC adipogenesis under normal conditions. The low levels of differentiation observed with ischaemic MSCs was most likely because cell numbers had decreased so considerably. Perhaps the significantly increased differentiation levels associated with the HSP70-MSC group were due to the fact that HSP70 over-expression had a beneficial effect on cell survival, thereby preserving cell number.

\section{Conclusions}

The combination of mesenchymal stem cell therapy and gene therapy offers an integrated approach towards tissue and organ repair. The success of such a combined therapy is dependent on the optimum genetic modification of MSCs. Consequently, the present study is of particular interest and validates the choice and use of lentiviral vectors for this purpose. Here, we report that MSCs can be efficiently transduced in vitro to express either reporter gene or variety of therapeutic genes using a second generation lentiviral vector. This is, to our knowledge, the first study that systematically examines lentiviral vector-mediated gene modification of MSCs. Information arising from such experiments is crucial to the successful genetic modification of MSCs, which has the potential to augment their therapeutic benefit.

The integrative nature of lentiviral vectors does however raise concerns of a potential risk of insertional mutagenesis. In this regard, further investigation and clarification is required and the development of integration mapping techniques or targeted gene delivery to avoid potentially oncogenic sites has become desirable. The use of a non-integrating lentivirus vector is also an option - these vectors possess a mutated integrase gene, which results in transient gene expression. Further development in this area offers the possibility to develop a novel gene-transfer vector that does not pose the risk associated with permanent integration into host cells, yet possesses the efficiency of lentiviral vectors that is required for effective genetic modification. Despite these concerns, the value of lentivirus vectors cannot be completely discounted, as these vectors are currently unsurpassed in their efficiency of gene delivery to MSCs.

Additionally, we showed that lentivirus vector modification of MSCs can exert a functional effect through over-expression of HSP70 in an in vitro model of ischaemia. The use of only in vitro testing does however restrict what conclusions can be reached from the present study, as these findings may not translate to an in vivo situation. Therefore, further in vivo experiments based on this study are necessary for the identification of a potentially therapeutic factor for use in ex vivo stem cell therapy.

In conclusion, we report that lentivirus vectors are a valuable gene delivery tool and lentivirus-mediated genetic modification of MSCs has the potential to significantly augment the therapeutic benefit of MSC-based therapies.

\section{Additional material}

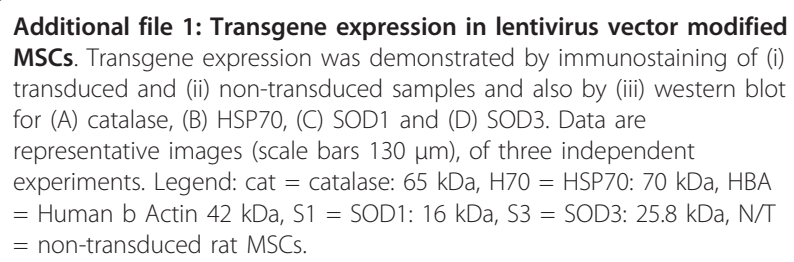

\section{Abbreviations}

2DG: 2-deoxyglucose; 5-aza-c: 5-azacytidine; CMV: cytomegalovirus, EF1-a: elongation factor 1 alpha; ESC: embryonic stem cell; GFP: green fluorescent protein; HDAC: histone deacetylase; HIV-1: human immunodeficiency virus-1; HSC: hematopoietic stem cell; HSP: heat shock protein; MFI: mean fluorescence intensity; MOI: multiplicity of infection; MSC: mesenchymal stem cell; PGK: phosphoglycerate kinase; SIN: self-inactivating; SOD: superoxide dismutase; TSA: trichostatin A; VSV-G: vesicular stomatitis virus glycoprotein.

\section{Acknowledgements}

We thank Georgina Shaw for her technical assistance. This work was funded by Science Foundation Ireland (SFI). 


\section{Author details}

'Regenerative Medicine Institute and Department of Medicine, National University of Ireland, Galway and Galway University Hospital, University Road, Galway. Ireland. ${ }^{2}$ Multiple Sclerosis \& Stroke Research Group, NCBES, National University of Ireland Galway, University Road, Galway, Ireland. ${ }^{3}$ School of Biomedical Sciences, Charles Sturt University, Boorooma Street, PO Box 588, Wagga Wagga, NSW 2678, Australia. ${ }^{4}$ Lung Biology Group, Department of Anaesthesia, NCBES, National University of Ireland, Galway, University Road, Galway, Ireland.

\section{Authors' contributions}

LMG produced lentiviral vectors, designed and conducted all experiments and drafted the manuscript. JMM participated in supervision and design of the study. DOT and PS participated in vector and experimental design. FB and MM participated in experimental design. TOB participated in supervision and study design and was the principal investigator. All authors carried out revisions of the manuscript and approved the final manuscript for submission.

\section{Competing interests}

TOB has received education grants from Pfizer, Novartis and Merck Ltd and has received research grants from Medtronic. The other authors declare no competing interests.

\section{Received: 21 October 2010 Accepted: 7 March 2011}

Published: 7 March 2011

\section{References}

1. Pittenger MF, Mackay AM, Beck SC, Jaiswal RK, Douglas R, Mosca JD, Moorman MA, Simonetti DW, Craig S, Marshak DR: Multilineage potential of adult human mesenchymal stem cells. Science 1999, 284:143-7.

2. Barry FP, Murphy JM: Mesenchymal stem cells: clinical applications and biological characterization. Int J Biochem Cell Biol 2004, 36:568-84.

3. Mahmood A, Lu D, Lu M, Chopp M: Treatment of traumatic brain injury in adult rats with intravenous administration of human bone marrow stromal cells. Neurosurgery 2003, 53:697-702, discussion 702-3.

4. Ryan JM, Barry F, Murphy JM, Mahon BP: Interferon-gamma does not break, but promotes the immunosuppressive capacity of adult human mesenchymal stem cells. Clin Exp Immunol 2007, 149:353-63.

5. Ryan JM, Barry FP, Murphy JM, Mahon BP: Mesenchymal stem cells avoid allogeneic rejection. J Inflamm (Lond) 2005, 2:8.

6. Aggarwal S, Pittenger MF: Human mesenchymal stem cells modulate allogeneic immune cell responses. Blood 2005, 105:1815-22.

7. Sotiropoulou PA, Papamichail M: Immune properties of mesenchymal stem cells. Methods Mol Biol 2007, 407:225-43.

8. George JC: Stem cell therapy in acute myocardial infarction: a review of clinical trials. Trans/ Res 155:10-9.

9. Mylotte LA, Duffy AM, Murphy M, O'Brien T, Samali A, Barry F, Szegezdi E: Metabolic flexibility permits mesenchymal stem cell survival in an ischemic environment. Stem Cells 2008, 26:1325-36.

10. Hoare M, Greiser U, Schu S, Mashayekhi K, Aydogan E, Murphy M, Barry F, Ritter T, O'Brien T: Enhanced lipoplex-mediated gene expression in mesenchymal stem cells using reiterated nuclear localization sequence peptides. Gene Med 12:207-18.

11. McMahon JM, Conroy S, Lyons M, Greiser U, O'shea C, Strappe P, Howard L, Murphy M, Barry F, O'Brien T: Gene transfer into rat mesenchymal stem cells: a comparative study of viral and nonviral vectors. Stem Cells Dev 2006, 15:87-96.

12. Naldini L: Lentiviruses as gene transfer agents for delivery to nondividing cells. Curr Opin Biotechnol 1998, 9(5):457-63.

13. Naldini L, Blömer U, Gallay P, Ory D, Mulligan R, Gage FH, Verma IM, Trono D: In vivo gene delivery and stable transduction of nondividing cells by a lentiviral vector. Science 1996, 272:263-7.

14. Neuhuber B, Gallo G, Howard L, Kostura L, Mackay A, Fischer I: Reevaluation of in vitro differentiation protocols for bone marrow stromal cells: disruption of actin cytoskeleton induces rapid morphological changes and mimics neuronal phenotype. $J$ Neurosci Res 2004, 77:192-204.

15. Neuhuber B, Swanger SA, Howard L, Mackay A, Fischer I: Effects of plating density and culture time on bone marrow stromal cell characteristics. Exp Hematol 2008, 36:1176-85.
16. Scutt A, Bertram P: Basic fibroblast growth factor in the presence of dexamethasone stimulates colony formation, expansion, and osteoblastic differentiation by rat bone marrow stromal cells. Calcif Tissue Int 1999, 64:69-77.

17. Mosmann T: Rapid colorimetric assay for cellular growth and survival: application to proliferation and cytotoxicity assays. J Immunol Methods 1983, 65:55-63.

18. Forte A, Napolitano MA, Cipollaro M, Giordano A, Cascino A, Galderisi U: An effective method for adenoviral-mediated delivery of small interfering RNA into mesenchymal stem cells. J Cell Biochem 2007, 100:293-302.

19. Lou J, Xu F, Merkel K, Manske P: Gene therapy: adenovirus-mediated human bone morphogenetic protein-2 gene transfer induces mesenchymal progenitor cell proliferation and differentiation in vitro and bone formation in vivo. J Orthop Res 1999, 17:43-50.

20. Kumar S, Mahendra G, Nagy TR, Ponnazhagan S: Osteogenic differentiation of recombinant adeno-associated virus 2-transduced murine mesenchymal stem cells and development of an immunocompetent mouse model for ex vivo osteoporosis gene therapy. Hum Gene Ther 2004, 15:1197-206.

21. Song L, Chau L, Sakamoto Y, Nakashima J, Koide M, Tuan RS: Electric fieldinduced molecular vibration for noninvasive, high-efficiency DNA transfection. Mol Ther 2004, 9:607-16.

22. Gelse K, Von der Mark K, Aigner T, Park J, Schneider H: Articular cartilage repair by gene therapy using growth factor-producing mesenchymal cells. Arthritis Rheum 2003, 48:430-41.

23. Kyriakou CA, Yong KL, Benjamin R, Pizzey A, Dogan A, Singh N, Davidoff AM, Nathwani AC: Human mesenchymal stem cells (hMSCs) expressing truncated soluble vascular endothelial growth factor receptor (tsFlk-1) following lentiviral-mediated gene transfer inhibit growth of Burkitt's lymphoma in a murine model. J Gene Med 2006, 8:253-64.

24. Worsham DN, Schuesler T, Von Kalle C, Pan D: In vivo gene transfer into adult stem cells in unconditioned mice by in situ delivery of a lentiviral vector. Mol Ther 2006, 14:514-24.

25. Challita PM, Kohn DB: Lack of expression from a retroviral vector after transduction of murine hematopoietic stem cells is associated with methylation in vivo. Proc Natl Acad Sci USA 1994, 91:2567-71.

26. Jähner D, Stuhlmann H, Stewart CL, Harbers K, Löhler J, Simon I, Jaenisch R: De novo methylation and expression of retroviral genomes during mouse embryogenesis. Nature 1982, 298:623-8.

27. Stewart CL, Stuhlmann H, Jähner D, Jaenisch R: De novo methylation, expression, and infectivity of retroviral genomes introduced into embryonal carcinoma cells. Proc Natl Acad Sci USA 1982, 79:4098-102.

28. Teich NM, Weiss RA, Martin GR, Lowy DR: Virus infection of murine teratocarcinoma stem cell lines. Cell 1977, 12:973-82.

29. Hino S, Fan J, Taguwa S, Akasaka K, Matsuoka M: Sea urchin insulator protects lentiviral vector from silencing by maintaining active chromatin structure. Gene Ther 2004, 11:819-28.

30. Ma Y, Ramezani A, Lewis R, Hawley RG, Thomson JA: High-level sustained transgene expression in human embryonic stem cells using lentiviral vectors. Stem Cells 2003, 21:111-7.

31. Pfeifer A, lkawa M, Dayn $Y$, Verma IM: Transgenesis by lentiviral vectors: lack of gene silencing in mammalian embryonic stem cells and preimplantation embryos. Proc Natl Acad Sci USA 2002, 99:2140-5.

32. Ramezani A, Hawley TS, Hawley RG: Performance- and safety-enhanced lentiviral vectors containing the human interferon-beta scaffold attachment region and the chicken beta-globin insulator. Blood 2003, 101:4717-24.

33. Xia X, Zhang Y, Zieth CR, Zhang SC: Transgenes delivered by lentiviral vector are suppressed in human embryonic stem cells in a promoterdependent manner. Stem Cells Dev 2007, 16:167-76.

34. Liu HS, Jan MS, Chou CK, Chen PH, Ke NJ: Is green fluorescent protein toxic to the living cells? Biochem Biophys Res Commun 1999, 260:712-7.

35. Van Damme A, Thorrez L, Ma L, Vandenburgh H, Eyckmans J, Dell'Accio F, De Bari C, Luyten F, Lillicrap D, Collen D, VandenDriessche T, Chuah MK: Efficient lentiviral transduction and improved engraftment of human bone marrow mesenchymal cells. Stem Cells 2006, 24:896-907.

36. Tsuda H, Wada T, Ito Y, Uchida H, Dehari H, Nakamura K, Sasaki K, Kobune M, Yamashita T, Hamada H: Efficient BMP2 gene transfer and bone formation of mesenchymal stem cells by a fiber-mutant adenoviral vector. Mol Ther 2003, 7:354-65. 
37. Neely JR, Whitmer JT, Rovetto MJ: Inhibition of glycolysis in hearts during ischemic perfusion. Recent Adv Stud Cardiac Struct Metab 1975, 7:243-8.

38. Rovetto MJ, Lamberton WF, Neely JR: Mechanisms of glycolytic inhibition in ischemic rat hearts. Circ Res 1975, 37:742-51.

39. Zhu W, Chen J, Cong X, Hu S, Chen X: Hypoxia and serum deprivationinduced apoptosis in mesenchymal stem cells. Stem Cells 2006, 24:416-25.

40. Bialik S, Cryns VL, Drincic A, Miyata S, Wollowick AL, Srinivasan A, Kitsis RN: The mitochondrial apoptotic pathway is activated by serum and glucose deprivation in cardiac myocytes. Circ Res 1999, 85:403-14.

41. Bonavita F, Stefanelli C, Giordano E, Columbaro M, Facchini A, Bonafè F, Caldarera CM, Guarnieri C: H9c2 cardiac myoblasts undergo apoptosis in a model of ischemia consisting of serum deprivation and hypoxia: inhibition by PMA. FEBS Lett 2003, 536:85-91.

42. Chao W, Shen Y, Li L: Rosenzweig A, Importance of FADD signaling in serum deprivation- and hypoxia-induced cardiomyocyte apoptosis. J Biol Chem 2002, 277:31639-45.

43. Grayson WL, Zhao F, Bunnell B, Ma T: Hypoxia enhances proliferation and tissue formation of human mesenchymal stem cells. Biochem Biophys Res Commun 2007, 358:948-53.

44. Grayson WL, Zhao F, Izadpanah R, Bunnell B, Ma T: Effects of hypoxia on human mesenchymal stem cell expansion and plasticity in $3 \mathrm{D}$ constructs. J Cell Physiol 2006, 207:331-9.

45. Ren H, Cao Y, Zhao Q, Li J, Zhou C, Liao L, Jia M, Zhao Q, Cai H, Han ZC, Yang R, Chen G, Zhao RC: Proliferation and differentiation of bone marrow stromal cells under hypoxic conditions. Biochem Biophys Res Commun 2006, 347:12-21.

46. Lennon DP, Edmison JM, Caplan Al: Cultivation of rat marrow-derived mesenchymal stem cells in reduced oxygen tension: effects on in vitro and in vivo osteochondrogenesis. J Cell Physiol 2001, 187:345-55.

47. Kofoed H, Sjøntoft E, Siemssen SO, Olesen HP: Bone marrow circulation after osteotomy. Blood flow, pO2, pCO2, and pressure studied in dogs. Acta Orthop Scand 1985, 56:400-3.

doi: $10.1186 /$ scrt53

Cite this article as: McGinley et al: Lentiviral vector mediated modification of mesenchymal stem cells \& enhanced survival in an in vitro model of ischaemia. Stem Cell Research \& Therapy 2011 2:12.

\section{Submit your next manuscript to BioMed Central and take full advantage of:}

- Convenient online submission

- Thorough peer review

- No space constraints or color figure charges

- Immediate publication on acceptance

- Inclusion in PubMed, CAS, Scopus and Google Scholar

- Research which is freely available for redistribution

Submit your manuscript at www.biomedcentral.com/submit
Biomed Central 